.

\title{
CASO DE ENSINO SOBRE O HOTELZINHO DOCE ENCANTO: O LADO NÃO TÃO DOCE DA RELAÇÃO ENTRE ESTRUTURA, ESTRATÉGIA E SOBREVIVÊNCIA ORGANIZACIONAL
}

DOI: 1014211/regepe33008

\author{
José Vitor Palhares dos Santos - Universidade Federal De Minas Gerais ${ }^{1}$
}

Resumo: Este caso de ensino sobre o Centro Educacional Hotelzinho Doce Encanto se destina, sobretudo, aos cursos de graduação e pós-graduação em Administração. Tem como objetivo relatar os processos estruturais e administrativos de uma empresa, relacionando-os com uma vertente teórica da área, as chamadas Teorias Ambientais, principalmente no que se refere à estrutura, estratégia e sobrevivência organizacional. $O$ presente trabalho é baseado em uma história verídica e foi construído mediante entrevista semiestruturada com a proprietária e gestora da empresa pesquisada, situada em Sacramento-MG. Os dados foram levantados por meio da trajetória de vida da profissional e análise de documentos e relatórios disponibilizados, sendo tratados através da análise de conteúdo. Neste estudo, são exploradas as contingências pelas quais a proprietária do estabelecimento está vivenciando, o que possibilita aos discentes, uma ampliação de conhecimentos e habilidades de análise sobre a relação entre as teorias e as realidades praticadas na gestão da organização, auxiliando-os em uma reflexão sobre as práticas de gestão e diagnósticos empresariais, e a sua relação com as teorias administrativas.

Palavras-chave: Caso de ensino; Estrutura; Estratégia; Sobrevivência organizacional; Teorias Ambientais.

\section{TEACHING CASE ABOUT THE SWEET CHARMING LITTLE NURSERY: THE SIDE NOT SO SWEET OF THE RELATION BETWEEN STRUCTURE, STRATEGY AND ORGANIZATIONAL SURVIVAL}

\begin{abstract}
This teaching case about the Sweet Charming Little Nursery Educational Center is primarily destined for undergraduate and postgraduate courses of Administration. It aims to report the structural and administrative processes of a business, linking them with a theoretical approach of area, the Environmental Theories, mainly in relation to the structure, strategy and organizational survival. The case is based on a true story and it was constructed by semi-structured interview with the owner and manager of the enterprise, which is located in Sacramento, MG. The data were collected by means of the life trajectory of owner and analysis of documents and reports available, being treated by content analysis. This study explored the contingencies for which the owner of the business is experiencing, that allows students to an expansion of knowledge and skills of analysis about the relation between the theories and the realities practiced in the management of the organization,
\end{abstract}

\footnotetext{
${ }^{1}$ E.mail: titopalhares@hotmail.com - Endereço: Av. Antônio Carlos, 6627 / sala 4012 - Pampulha Belo Horizonte - MG, CEP: 31270-901.
}

SANTOS, J. V. P. Caso de ensino sobre o hotelzinho doce encanto: o lado não tão doce da relação entre estrutura, estratégia e sobrevivência organizacional. Revista de

Empreendedorismo e Gestão de Pequenas Empresas, v.3, n.3, p. 211-223, 2014. 
helping them in a reflection about management practices and business diagnostics, and their relationship with management theories.

Keywords: Teaching case; Structure; Strategy; Organization survival; Environmental Theories.

\section{Da insatisfação à busca pela inovação: como tudo começou}

Helenice dos Santos sempre morou na cidade de Sacramento (MG), onde, atualmente, gerencia a sua própria empresa, o Hotelzinho Doce Encanto. Mas antes de ela entrar no enredo principal deste trabalho é necessário contar como se desenvolveu o processo da estratégia de criar esse negócio.

Lena, como gosta de ser chamada, ao mesmo tempo em que cursava a faculdade de Letras, trabalhava na Câmara Municipal de sua cidade, e até chegou a lecionar algumas aulas nas escolas públicas e particulares dali. Entretanto, o que ela realmente gostava era de trabalhar no cargo de confiança que Ihe foi atribuído na Câmara, onde permaneceu durante vinte anos. No ano de 2006 foi demitida pelo presidente que assumiu o mandato na época.

Após a sua demissão, Lena atuou apenas como professora de Português e Literatura do Ensino Médio e Fundamental até o ano de 2008, ano em que, com a mudança do presidente da Câmara, foi chamada novamente para assumir o seu antigo cargo de confiança que exercera. Devido ao fato de se identificar com o trabalho que desempenhou durante duas décadas e também pelos benefícios e salário oferecido, Lena aceitou a proposta e voltou a trabalhar no órgão municipal de sua cidade.

Entretanto, com uma nova eleição e mudança na presidência no ano de 2010, ela foi demitida novamente do cargo de confiança, o que a deixou insatisfeita com a situação que estava vivenciando, ou seja, trabalhando em um cargo totalmente instável, em uma circunstância na qual a cada dois anos se via obrigada a mudar completamente sua rotina pessoal e profissional.

Foi a partir daí que surgiu a "mulher empreendedora", como ela mesma se apelidou. Vinda de uma família que há tempos atrás tinha seu pai como dono de uma mercearia que não teve sucesso, Lena nunca escondeu o desejo de abrir o seu

SANTOS, J. V. P. Caso de ensino sobre o hotelzinho doce encanto: o lado não tão doce da relação entre estrutura, estratégia e sobrevivência organizacional. Revista de

Empreendedorismo e Gestão de Pequenas Empresas, v.3, n.3, p. 211-223, 2014. 
próprio negócio, por acreditar que o "sangue de comerciante, familiar, corre em suas veias", conforme menciona na própria entrevistada.

Foi da insatisfação de um trabalho instável que veio, então, a oportunidade de abrir a sua própria empresa. Cansada da dependência na qual era submetida nos anos eleitorais da Câmara Municipal, pelo fato de se considerar empreendedora e pela vontade de ser sua própria chefe, Lena resolveu que iria abrir um negócio inovador em sua cidade. Mas qual negócio seria esse?

Depois de muito escutar as opiniões de seu marido, irmãos, mãe e filhos, Lena optou por abrir, em Sacramento (MG), uma escolinha de Educação Infantil para crianças de zero até cinco anos de idade, opção esta que não condizia com a opinião da maioria de seus familiares.

Entretanto, ela realmente se decidiu por essa alternativa devido a três principais motivos, a saber: o primeiro é o motivo que mais interferiu em sua escolha, como também foi o fator que a fez enxergar essa possibilidade de ramo de trabalho. Lena virou avó no ano de 2009 e percebeu que era difícil deixar a criança aos cuidados de alguém ou em creches na cidade. Este era o primeiro motivo. $O$ segundo motivo que ela vislumbrou, foi uma fatia de mercado relevante para a sua atuação. Por último, também considerou como sendo um negócio inovador, visto que, além da pouca concorrência existente na cidade, ela também ofereceria serviços diferenciados dos demais já consolidados no mercado.

Dessa forma, ainda no ano de 2010, Lena começou a planejar e a estruturar a sua empresa, a fim de que pudesse ser aberta já no ano seguinte, em 2011, quando aconteceu de fato a sua inauguração. Das demissões e insatisfação de um trabalho instável, surge então, a possibilidade de empreender. Lena, que sempre quis abrir seu próprio comércio, optou por abrir uma empresa prestadora de serviços educacionais infantis. E assim, inicia-se a história de um negócio cuja proprietária almeja sua realização profissional, inicia-se juntamente a trajetória do Hotelzinho Doce Encanto.

SANTOS, J. V. P. Caso de ensino sobre o hotelzinho doce encanto: o lado não tão doce da relação entre estrutura, estratégia e sobrevivência organizacional. Revista de

Empreendedorismo e Gestão de Pequenas Empresas, v.3, n.3, p. 211-223, 2014. 
Hotelzinho doce encanto: contextualização e problematização

Historicamente, as creches foram criadas no Brasil como um trabalho assistencial-custodial para as populações de baixa renda, prestando serviços de higiene, alimentação e segurança física das crianças. Porém, atualmente, tal assistencialismo divide espaço com a missão educacional das creches, as quais estão organizando sua programação de forma a contemplar as atividades pedagógicas (VERÍSSIMO; FONSECA, 2003).

De acordo com a UNESCO (2005), nas últimas décadas, as pesquisas têm corroborado para o fato de que do nascimento até os seis primeiros anos de vida de uma criança é um período de intenso aprendizado e desenvolvimento. Nesse sentido, os centros de Educação Infantil de qualidade é o investimento mais expressivo na área social do que qualquer outro. É um fator de extrema importância, tanto no curto, médio como também no longo prazo, no que tange aos benefícios educacionais, econômicos e sociais.

O Hotelzinho Doce Encanto é um Centro Educacional Infantil localizado na cidade de Sacramento (MG). Lena recebeu a autorização da Secretaria de Educação do Estado de Minas Gerais para que pudesse abri-lo no dia 29 de julho de 2011, através da portaria $\mathrm{n} \cong$ 11/2011. Antes disso, ela trabalhava nas questões estruturais do mesmo, reformando-o dentro das exigências da Vigilância Sanitária e do Corpo de Bombeiros. Seu nome fantasia, Hotelzinho Doce Encanto, foi uma ideia conjunta com seus familiares e o objetivo da organização é a prestação de serviços educacionais infantis para crianças de zero a cinco anos de idade.

Atualmente, a empresa conta, além da proprietária, com mais três funcionárias, sendo elas: a auxiliar de serviços gerais, uma cozinheira e uma professora. A estrutura física do estabelecimento é formada por quatorze cômodos não muito grandes para atender a demanda de seus clientes. Estão inclusos nesse número: refeitórios, berçários, brinquedotecas, banheiros e bebeteca, além de uma área verde e outra área coberta com piscina.

Em relação ao mercado de trabalho, Lena enxerga apenas duas empresas que prestam serviços semelhantes e também particulares. Mas ela acredita diferenciar-se de seus concorrentes devido ao portfólio de serviços prestados, 
horário de atendimento e também pelo fato de cuidar de recém-nascidos, serviço este que as demais não oferecem, cuidando de crianças apenas de três anos em diante. Entretanto, há também outras duas creches na cidade oferecidas pelo município, não tendo a necessidade de um pagamento mensal para receber as crianças. Lena enxerga esses centros como um trabalho de cunho mais assistencialista do que educacional e tem definido que o público-alvo da sua organização é outro, é aquele que pode pagar.

Dentre os serviços oferecidos pelo Hotelzinho Doce Encanto, estão a higiene, a educação, a alimentação e o lazer das crianças. Lena destaca como diferencial da sua empresa: o lazer, por possuir uma piscina e um amplo espaço verde para as crianças brincarem; o preço, condizente com o que vigora no mercado em Sacramento; o horário de atendimento, pois enquanto os outros estabelecimentos fecham às 17 horas, ela fecha às 18h30min, além de abrir também nas férias; o portfólio diferenciado de serviços prestados, principalmente no que se refere à alimentação; e aceitar crianças recém-nascidas.

Lena concorda que a rotina dentro da organização é, muitas vezes, estressante. Cuidar de criança, segundo ela, dá trabalho, mas mesmo assim diz amar o que faz. Outra questão difícil que às vezes se depara é a compreensão dos pais quando as crianças se machucam e o relacionamento com suas funcionárias, muitas vezes desgastante.

No que concerne ao planejamento da empresa, Lena explica que não fez um plano de negócios para a validação da sua ideia, mas enxergou uma fatia de mercado que está preocupada em deixar seus filhos com babás em casa, devido a possíveis atos de violência e despreparo para lidar com crianças. Dessa forma, a empresa não possui missão, visão e valores formais, nem um site institucional, embora compreenda e saiba ressaltar claramente qual são os objetivos da organização, que é cuidar da educação, higiene, alimentação e lazer de seus clientes, com qualidade e excelência.

Em relação aos indicadores financeiros e a parte contábil empresarial, Lena explica que, como não tem conhecimento da área, sempre que possui alguma dúvida recorre ao seu irmão, que entende do assunto. Além disso, caso se depare com alguma dificuldade maior, que precise de mais discussão para resolver, Lena

SANTOS, J. V. P. Caso de ensino sobre o hotelzinho doce encanto: o lado não tão doce da relação entre estrutura, estratégia e sobrevivência organizacional. Revista de

Empreendedorismo e Gestão de Pequenas Empresas, v.3, n.3, p. 211-223, 2014. 
procura o apoio de sua família. É importante ressaltar que ela nunca procurou por consultorias organizacionais.

Ultimamente, Lena tem se deparado com uma questão que a tem feito pensar bastante sobre o futuro do seu negócio: o número de crianças (clientes) que possui em relação à estrutura e estratégias da empresa. Lena possui atualmente um número relativamente estável e relevante de clientes, mas para atendê-los de uma forma mais eficiente, seria necessário aumentar a estrutura da organização. Além disso, com o atual número de clientes que possui, Lena não está satisfeita com o pró-labore que está recebendo, em vista do trabalho que tem na empresa. Dessa forma, uma das estratégias para a continuidade do negócio seria aumentar sua estrutura organizacional como uma forma de poder acolher mais crianças e, consequentemente, também aumentar o lucro da empresa e se manter no mercado.

Porém, com o espaço alugado que possui, Lena não consegue aumentar sua estrutura. Seria necessário procurar outro local para dar continuidade ao seu negócio. Como a empresa está localizada na região central da cidade e por considerá-la um ótimo ponto em questão de localização, Lena não sabe se muda a organização de local. Além disso, ela já entrou em contato com diversas pessoas que estão alugando um ponto comercial, mas nunca encontrou outro lugar do seu gosto, ora devido à má localização, ora ao preço do aluguel ser muito caro, diferentemente do atual preço que paga pelo cômodo alugado.

Assim, Lena possui um dilema relacionado à estratégia e ao futuro da organização que nem seus familiares estão conseguindo ajudar resolver: se a proprietária deve ou não mudar seu estabelecimento de local ou se ela resolve fechar a organização, uma vez que, no estágio atual, não traz os benefícios esperados.

Embora a organização tenha mantido certo número relevante de clientes e por isso mesmo está necessitando de um espaço maior para continuar sua prestação de serviços, essa quantia não tem sido suficiente para gerar os lucros esperados por Lena, que pensa em fechá-la. Contudo, ter seu próprio negócio é sinônimo, para ela, de realização pessoal e profissional.

SANTOS, J. V. P. Caso de ensino sobre o hotelzinho doce encanto: o lado não tão doce da relação entre estrutura, estratégia e sobrevivência organizacional. Revista de

Empreendedorismo e Gestão de Pequenas Empresas, v.3, n.3, p. 211-223, 2014. 
Notas de ensino

\section{Objetivos de aprendizagem e indicação do público para uso do caso de ensino}

O caso do Centro Educacional Hotelzinho Doce Encanto se destina, sobretudo, aos cursos de graduação e pós-graduação de Administração, uma vez que busca relatar os processos estruturais e administrativos de uma empresa, relacionando-os com uma vertente teórica da área, as chamadas Teorias Ambientais, principalmente no que se refere à estrutura, estratégia e sobrevivência organizacional.

Além disso, o caso ainda pode ser indicado para estudos sobre a relevância de ferramentas administrativas, como o Plano de Negócios e o Planejamento Estratégico, para a sobrevivência empresarial no mercado como um todo. Nesse contexto, são exploradas as contingências pelas quais a proprietária do estabelecimento está vivenciando. Isto possibilita aos alunos uma ampliação de conhecimentos e habilidades de análise sobre a relação entre as teorias e as realidades praticadas na gestão da organização, auxiliando-os em uma reflexão sobre as práticas de gestão e diagnósticos empresariais, e a sua relação com as teorias administrativas.

\section{Fontes dos dados}

Este relato de caso é baseado em uma história verídica e foi construído mediante uma entrevista semiestruturada com a proprietária e gestora da empresa Hotelzinho Doce Encanto, situada em Sacramento-MG. Os dados foram levantados por meio da trajetória de vida da profissional, fazendo um recorte para os anos que embasaram o caso. Além disso, utilizou-se também da análise documental de alguns relatórios que foram disponibilizados para o autor do caso de ensino, os quais possibilitaram um melhor acompanhamento da trajetória da empresa.

SANTOS, J. V. P. Caso de ensino sobre o hotelzinho doce encanto: o lado não tão doce da relação entre estrutura, estratégia e sobrevivência organizacional. Revista de

Empreendedorismo e Gestão de Pequenas Empresas, v.3, n.3, p. 211-223, 2014. 
Aspectos pedagógicos

A sugestão para a aplicação do presente caso de ensino é em uma aula dividida em duas etapas. Considerando que uma explicação mais aprofundada sobre as Teorias Ambientais já tenha sido feita anteriormente, a primeira parte da dinâmica da aula seria pedir aos alunos que formassem um círculo na sala para debater e explorar os principais aspectos abordados pelas Teorias Ambientais da Administração, principalmente no que se refere à estrutura, estratégia e sobrevivência organizacional, alinhados às teorias que tratam sobre cada assunto. $O$ professor deve assumir o papel de estimular um pensamento crítico nos alunos.

Após, o docente explicaria aos alunos o estudo de caso e a problematização da organização. Na etapa seguinte, sugere-se dividir a turma em pequenos grupos, de forma que eles debatam entre si, questões específicas direcionadas pelo professor, identificando os principais problemas encontrados na empresa e propondo soluções, colocando-os na posição de consultores para a análise do caso e expondo, posteriormente, os resultados para o restante da turma.

\section{Questões para discussão}

1. Quais as principais contingências enfrentadas pelo Hotelzinho Doce Encanto?

2. No presente caso, a estratégia irá determinar a estrutura ou a estrutura irá determinar a estratégia?

3. A organização pode ser considerada mais mecanicista ou organicista? Por quê?

4. Alguns erros estruturais e melhor posicionamento estratégico poderiam ser evitados com a elaboração de um Planejamento Estratégico? Se sim, quais?

5. Como a condição e o meio em que a organização está inserida irão influenciar na criação de uma estratégia para o futuro da empresa?

6. Em que ponto a Teoria da Dependência de Recursos se relaciona com o caso vivenciado pela proprietária do estabelecimento?

7. Como a Teoria da Ecologia Organizacional pode explicar a atual situação da organização?

SANTOS, J. V. P. Caso de ensino sobre o hotelzinho doce encanto: o lado não tão doce da relação entre estrutura, estratégia e sobrevivência organizacional. Revista de

Empreendedorismo e Gestão de Pequenas Empresas, v.3, n.3, p. 211-223, 2014. 
8. Como os autores que criticam as Teorias Ambientais visualizariam a problematização do Hotelzinho Doce Encanto?

9. Analise o caso na percepção de um consultor e sugira soluções.

\section{Exposição Teórica}

Esta seção contempla o esforço em apresentar as principais bases teóricas que envolvem o caso de ensino. Dessa forma, serão apresentadas a seguir, teorias da Administração, as quais se sugerem trabalhar o presente estudo. Tais teorias estão distribuídas em um tópico mais macro e abrangente sobre as Teorias Ambientais, mas que terão suas vertentes detalhadas de forma a fazer uma relação com o caso de ensino.

De acordo com Hatch (1997), o período inicial dos estudos ambientais na Teoria das Organizações foi delineado pela Teoria Contingencial. Posteriormente, são desenvolvidas no segundo período outras três principais teorias que relacionam a organização e o ambiente: a Teoria da Dependência de Recursos, Ecologia Populacional e a Teoria Institucional. Entretanto, no presente estudo, o foco será dado até a Teoria da Ecologia das Populações.

A fase inicial das Teorias Organizacionais, centrada em pesquisas voltadas para o ambiente interno organizacional, como a Escola Clássica e de Relações Humanas, foi sobreposta por uma nova corrente de estudos conduzidos durante os anos 60 e 70, que passaram a ver a organização enquanto um organismo biológico, que está inserido em um ambiente e que interage com este (DONALDSON, 1999; MORGAN, 2009; HATCH, 1997).

A Teoria da Contingência rege que não há uma estrutura organizacional única que seja adequada a todos os tipos de organizações. A hipótese central dessa perspectiva é que em organizações de ambientes estáveis, com tarefas de baixa incerteza, as atividades são executadas mais eficazmente por meio de uma hierarquia centralizada, com trabalho rotineiro e distinção de áreas para a definição de responsabilidades. Já em ambientes instáveis e de inovações constantes, desenvolvem-se as chamadas organizações orgânicas, nas quais há maior

SANTOS, J. V. P. Caso de ensino sobre o hotelzinho doce encanto: o lado não tão doce da relação entre estrutura, estratégia e sobrevivência organizacional. Revista de

Empreendedorismo e Gestão de Pequenas Empresas, v.3, n.3, p. 211-223, 2014. 
diversificação de tarefas, menor formalização de cargos e hierarquia mais planificada (HATCH, 1997; DONALDSON, 1999; CHANDLER, 1962).

Analisando-se as descrições, percebe-se que, na Teoria Contingencial, os ambientes estáveis seriam mais favoráveis ao estabelecimento de uma organização com base nos moldes da Teoria Clássica, enquanto que em ambientes instáveis, o modo ideal de organização seria aquele mais próximo do que rege a Escola de Relações Humanas. Neste sentido, houve uma tentativa de aproximar as duas abordagens contraditórias da Administração, sem o julgamento de qual das duas formas seria universalmente superior, sendo, cada uma, a mais apropriada em determinadas condições ambientais $(\mathrm{HATCH}, 1997$; DONALDSON, 1999; CHANDLER, 1962).

Outro autor relevante da Teoria Contingencial foi Chandler (1998). Ele desenvolveu um grande estudo acerca das estratégias de quatro grandes empresas norte-americanas: Du Pont, GM, Jersey Standard e Sears. Sua ideia era estabelecer a relação entre a estratégia adotada pelas organizações e sua estrutura, e qual fator era condicionante do outro.

Segundo Chandler (1962), como pressuposto básico da abordagem contingencial, a estratégia determina a estrutura. A relevância desse enfoque está na ideia de que se faz necessária a adequação entre estratégia e estrutura para um bom desempenho da organização no mercado (DONALDSON, 1999). Os estudos de Chandler (1998) corroboraram com a ideia de que as pressões tecnológicas e de mercado direcionam e impulsionam as empresas para adotarem determinadas estruturas organizacionais.

Chandler (1998) ainda defende a ideia de que as diferentes formas de organização são resultado de formas de expansão diferenciadas, partindo da consideração dessa expansão através de uma estratégia. Para a execução desta expansão, são criadas novas atividades, recursos e uma nova estrutura que propõe uma nova organização.

Vale destacar também que Chandler (1998) abriu a discussão de um tópico relevante sobre qual estratégia adotar para se ter um melhor desempenho. Tal fato mostra a relevância da Teoria Contingencial, que veio a se formar como conceito de

SANTOS, J. V. P. Caso de ensino sobre o hotelzinho doce encanto: o lado não tão doce da relação entre estrutura, estratégia e sobrevivência organizacional. Revista de

Empreendedorismo e Gestão de Pequenas Empresas, v.3, n.3, p. 211-223, 2014. 
Desempenho Organizacional e também como um o Planejamento Estratégico, uma ferramenta de gestão imprescindível para as organizações.

Por outro lado, há outros estudiosos, tais como Hall e Saias (1980), que defendem a ideia de que a estrutura leva à estratégia, e não o contrário. Logo, notase que não há um consenso entre os teóricos. No entanto, será que há uma resposta definitiva para essa contradição? Ao que parece, tanto a estratégia irá determinar em parte como se estruturam processos, pessoas e atividades organizacionais, como também a escassez de recursos, o histórico e a cultura organizacional também irão delimitar e direcionar as possibilidades reais de estratégia da organização.

De acordo com Donaldson (1999), há críticos que rejeitam o determinismo situacional, afirmando que os administradores têm livre escolha para determinar o rumo estratégico da organização, independentemente de uma imposição ambiental. Um exemplo deste argumento é que em uma corporação em posição de mercado dominante (monopólio ou oligopólio), os administradores podem conservar uma estrutura inadequada, se assim o desejarem, por um longo tempo, por justificativas pessoais ou para evitar conflitos e desgastes da equipe.

Além disso, há casos em que a própria administração da organização pode alterar o ambiente, tornando-o mais favorável a seus objetivos (DONALDSON, 1999). Dessa forma, torna-se pertinente a ressalva de Hickson e Pugh (2004) de que pessoas, e não organizações possuem objetivos. Tal consideração reflete a imprevisibilidade, arbitrariedade e inconstância que as decisões humanas podem manifestar.

Conforme destaca Chandler (1962), os administradores raramente alteram sua rotina diária e suas posições de poder, exceto quando fortemente pressionados. Assim, a adaptação da empresa às novas situações de mudança não se processa automaticamente, havendo muitos fatores que atuam contra ela. Dentre estes fatores, pode-se citar: a existência de uma estrutura organizacional adequada a uma fase preliminar de desenvolvimento, o que dificulta a adequação posterior; e a natureza multifacetada do envolvimento dos membros da organização quanto às suas carreiras, seus departamentos e suas subunidades especializadas. Estes fatores são frequentemente mais fortes do que o comprometimento e a visão da

SANTOS, J. V. P. Caso de ensino sobre o hotelzinho doce encanto: o lado não tão doce da relação entre estrutura, estratégia e sobrevivência organizacional. Revista de

Empreendedorismo e Gestão de Pequenas Empresas, v.3, n.3, p. 211-223, 2014. 
necessidade para a mudança dos profissionais na adaptação da estrutura organizacional (HICKSON; PUGH, 2004).

Em relação à Teoria da Dependência de Recursos, o argumento básico é que as análises de relações interorganizacionais podem ajudar aos gerentes a entenderem a relação entre poder e dependência que a disputa por recursos representam no ambiente de mercado. Este conhecimento permite que gerentes antecipem a sua necessidade de recursos - como matéria-prima, trabalho, capital, equipamento, conhecimentos - de acordo com as influências ambientais. Estes recursos são controlados pelo ambiente, que usa deste poder para fazer demandas para a organização, como preços competitivos, melhoria de produtos e/ou serviços, eficiência de processos organizacionais, dentre outros (HATCH, 1997).

Desta forma, conforme ressalta Donaldson (1999), a organização é vista como forçada a ajustar a sua estrutura a fatores materiais, como tamanho e tecnologia, enquanto ideias e valores não figuram proeminentemente como causas de mudança organizacional.

Para os teóricos da Ecologia das Organizações, a ideia de que as organizações podem adaptar-se aos seus ambientes atribui muito mais flexibilidade e poder à organização do que seria possível delas controlarem. Assim, focalizam a maneira pela qual os ambientes "selecionam" as organizações, enfatizando a importância das pressões inerciais que frequentemente impedem as organizações de mudança em resposta ao seu ambiente (MORGAN, 2009).

Assim como a Teoria da Dependência de Recursos, a ecologia populacional começa com a suposição de que as organizações dependem de seu ambiente para obter os recursos de que precisam para operar. No entanto, o que interessa à ecologia populacional não é a forma particular que a organização procura sua própria sobrevivência via competição por recursos escassos e críticos, mas sim os padrões de sucesso e fracassos dentre todas as organizações que competem dentro de determinado mercado, denominado como nicho (HATCH, 1997).

A Ecologia das Organizações é comparável à teoria da evolução das espécies de Darwin e, assim como a Teoria Contingencial, concebe as organizações como existindo em um estado constante de tensão e/ou de luta com os seus ambientes (HATCH, 1997). Para Morgan (2009), diversos críticos consideram a abordagem

SANTOS, J. V. P. Caso de ensino sobre o hotelzinho doce encanto: o lado não tão doce da relação entre estrutura, estratégia e sobrevivência organizacional. Revista de

Empreendedorismo e Gestão de Pequenas Empresas, v.3, n.3, p. 211-223, 2014. 
ecológica bastante determinística para oferecer explicação satisfatória de como as organizações realmente evoluem, visto que, não importa aquilo que os gerentes e os tomadores de decisão façam, a sobrevivência da organização seria ditada pelo processo de seleção natural. Isso justifica a crítica de Hatch (1997), que alega que essa teoria só seria aplicável a populações que são altamente competitivas, o que não é a totalidade dos diversos microambientes mercadológicos.

\section{Referências}

CHANDLER JR., A. D. Strategy and structure: chapters in the history of the American industrial enterprise. Cambridge, MA: MIT Press, 1962. 463 p.

CHANDLER JR., A. D. Ensaios para uma teoria histórica da grande empresa. Rio de Janeiro: FGV, 1998.

DONALDSON, L. Teoria da contingência estrutural. In: CLEGG, S. R.; HARDY, C.; NORD, W. R. (org) Handbook de estudos organizacionais: volume 1. São Paulo: Atlas, 1999.

HALL, D. J.; SAIAS, M. D. Strategy follows structure! In: Strategic Management Journal, n. 1, 1980, p. 149-163.

HATCH, M. J. Organization theory: modern simbolyc and postmodern perspectives. New York: Oxford University Press, 1997.

HICKSON, D. J.; PUGH, D. S. Alfred Chandler; Paul Lawrence e Jay Lorsch; Tom Burns. In: Rodrigues, S.B.; BARROS, B. T.; MEIRELLES, A.M.; AGUIAR, A. C. (Orgs). Os teóricos das organizações. Rio de Janeiro: Qualimark, 2004.

MORGAN, G. Imagens da Organização. São Paulo: Atlas, 2009. 421 p.

UNESCO. O Cotidiano no Centro de Educação Infantil. Cadernos Pedagógicos. v. 4. Brasília, 2005.

VERRÍSSIMO, M. R.; FONSECA, R. M. G. S. O cuidado da criança segundo trabalhadoras de creches. Revista Latino-americana de Enfermagem. São Paulo, jan./fev., 2003.

Artigo recebido em: 19/07/2014. Artigo aprovado em: 16/10/2014

SANTOS, J. V. P. Caso de ensino sobre o hotelzinho doce encanto: o lado não tão doce da relação entre estrutura, estratégia e sobrevivência organizacional. Revista de

Empreendedorismo e Gestão de Pequenas Empresas, v.3, n.3, p. 211-223, 2014. 